\title{
Correlation of Tumour Subtype With Long-term Outcome in Small Breast Carcinomas: A Swedish Population-based Retrospective Cohort Study
}

Gunilla Rask ( $\square$ gunillamrask@gmail.com )

Umeå Universitet Medicinska fakulteten: Umea Universitet Medicinska fakulteten https://orcid.org/0000-0002-0829-896X

Anoosheh Nazemroaya

Umeå Universitet Medicinska fakulteten: Umea Universitet Medicinska fakulteten

Malin Jansson

Umeå Universitet Medicinska fakulteten: Umea Universitet Medicinska fakulteten

\section{Charlotta Wadsten}

Umeå Universitet Medicinska fakulteten: Umea Universitet Medicinska fakulteten

\section{Greger Nilsson}

Uppsala University: Uppsala Universitet

Carl Blomqvist

University of Helsinki: Helsingin Yliopisto

Lars Holmberg

King's College London

Fredrik Wärnberg

Sahlgrenska University Hospital: Sahlgrenska universitetssjukhuset

Malin Sund

Umeå Universitet Medicinska fakulteten: Umea Universitet Medicinska fakulteten

\section{Research Article}

Keywords: Breast cancer, molecular subtypes, TMA, long-term outcome

Posted Date: May 4th, 2021

DOI: https://doi.org/10.21203/rs.3.rs-489830/v1

License: (c) (i) This work is licensed under a Creative Commons Attribution 4.0 International License.

Read Full License 


\section{Abstract}

Purpose: To investigate if molecular subtype is associated with outcome in stage 1 breast cancer (BC).

Method: Tissue samples from 445 women with node-negative BC $£ 15 \mathrm{~mm}$, treated in 1986-2004, were classified into surrogate molecular subtypes (Luminal A-like, Luminal B-like, Her2-positive, and triple negative breast cancer (TNBC)). Information on treatment, recurrences and survival were gathered from medical records.

Results: Tumour subtype was not associated with overall survival (OS). Luminal B-like and TNBC were associated with higher incidence of distant metastasis at 20 years. Luminal B-like and TNBC patients also had worse breast cancer specific survival (BCSS), although not statistically significant. Her2-positive $\mathrm{BC}$ was not associated with poor outcome despite no patient receiving Her2-targeted therapy.

Conclusions. Stage 1 TNBC or Luminal B-like tumours behave more aggressively. Women with Her2+/ER+ tumours do not have an increased risk of distant metastasis or death, absent targeted treatment.

\section{Introduction}

Most women with breast cancer (BC) are diagnosed with stage 1 disease in countries with generally available mammography screening and programmes for early detection [1] As a result, focus has shifted from clinical stage to tumour biology or molecular subtype of breast cancer when deciding on adjuvant systemic therapy. The surrogate molecular subtypes used in clinical practice are based on those originally described by Sørlie [2] and include Luminal A-like, Luminal B-like, Her2-positive (Her2+) and triple negative breast cancer (TNBC). All subtypes besides Luminal A implicate the patient is considered for adjuvant chemotherapy, with addition of targeted anti-Her2-therapy for the Her2 + tumours. However, most studies showing worse outcomes for these tumours and/or benefit of adjuvant chemotherapy and targeted anti-Her2 therapy included women with more advanced clinical stages of BC [3-5]. There are few studies on the potential independent prognostic value of tumour subtypes in women with small lymph node negative BC. [6-10] In these patients, the treatment benefit needs to be put into perspective of treatment induced morbidity since most women are long-term survivors. The prognostic value of different subtypes is also dependent on the length of follow-up, because the natural course of BC varies depending on subtype.

This study investigates the association of surrogate molecular subtypes with survival outcomes and recurrence in a cohort of Swedish women treated for small, lymph node negative BC between 1986-2004, a time period before multimodal treatment protocols were routine and before Her2-targeted therapy was approved for adjuvant BC treatment in Sweden.

\section{Materials And Method}

\section{Study cohort and generation of tissue microarray (TMA)}


The study cohort includes all women identified through the regional breast cancer quality of care registry and operated for unifocal BC with a radiological tumour size $\leq 15 \mathrm{~mm}$ at Uppsala university hospital or Västerås hospital between 1986 and 2004. The diagnosis and tumour size were verified through medical records. Additionally, the cohort includes women with breast carcinoma of any size operated at Uppsala university hospital 1986-2004 where the pathology report stated that there was an in situ-component as well as an invasive tumour. To generate a tissue microarray (TMA), we took two $1 \mathrm{~mm}$ core biopsies from the formalin fixed, paraffin embedded surgical resection specimens from each patient and embedded them in a recipient tissue block. A fully annotated pseudonymized clinical database included information on baseline characteristics, treatments, relapses and causes of death with data collected from a review of medical records every other year until March 2015. For the present study we excluded tumours where the final size on histology was $>15 \mathrm{~mm}$, or there were metastases to axillary lymph nodes. The Regional Ethics Committee of Uppsala approved the study (record number 99 422, 2005:118, and 2005:118/2).

\section{Histology}

The TMAs were sectioned and stained for haematoxylin-eosin, oestrogen receptor (ER), progesterone receptor (PR), Ki-67 and Her2 at the Department of Clinical pathology of Umeå University Hospital, using externally validated protocols according to clinical routine. For Her2 both immunohistochemistry and silver in situ hybridization (SISH) were performed. Two subspecialized breast pathologists at Umeå University Hospital (a tertiary care centre with approximately 1000 breast cancer cases/year), reviewed the slides. Expression of ER, PR, Ki67 and Her2 were scored separately by either pathologist, but the haematoxylin-eosin slides first separately and then together to reach consensus on the nuclear grade. For ER and PR, tumours were scored as positive $(\geq 10 \%)$ or negative $(<10 \%)$ and for Ki-67 as high $(\geq 10 \%)$ or low $(<10 \%)$. If a tumour had positive PR but missing an ER value because of technical reasons, the tumour was considered ER positive as well. Her2 IHC was scored as $0-3+$ and Her2 SISH as amplified/non-amplified respectively, both according to College of American Pathologists (CAP) guidelines 2018 [11] Nuclear grade was scored 1-3 according to Elston-Ellis [12]

\section{Surrogate molecular subtypes}

Based on the surrogate classification suggested by St Gallen and revised by Maissonneuve and Ehinger $[13,14]$ we divided the tumours into four subtypes as defined below. We used nuclear grade instead of histologic grade since neither tubule formation nor mitotic activity can be adequately assessed in biopsies of this size.

Luminal A-like (LumA): ER + or PR + with nuclear grade 1 or nuclear grade 2 with low Ki67.

Luminal B-like (LumB): ER + or PR + with nuclear grade 3 or nuclear grade 2 with high Ki67.

Her2-positive (Her2+): Her2-staining $3+$ by IHC and/or amplified by SISH.

Triple negative (TNBC): ER-, PR-, and Her2-.

\section{Statistics}


To compare baseline characteristics between the four groups we used chi square test or one-way analysis of variance (ANOVA). Primary outcomes were overall survival (OS), breast cancer specific survival (BCSS) and recurrence-free survival (RFS). Secondary outcomes were cumulative incidences of locoregional recurrence and distant metastasis. OS was defined as time from surgery to death from any cause. BCSS was defined as time from surgery to death primarily caused by BC as judged by the researcher reviewing the patients' medical records. Recurrence was defined as locoregional recurrence or distant metastasis as recorded in the medical records. RFS was defined as time from surgery to recurrence, and patients who died before recurrence were censored at the time of death. The reviewer of the medical records had no information on the subtype classification used in this study. The analyses of RFS and BCSS censored patients at the time of contralateral BC. The analysis of locoregional recurrence censored patients at the time of distant metastasis before locoregional recurrence. The analysis of distant metastasis censored patients at the time of contralateral BC before distant metastasis. To analyse survival outcomes and cumulative incidences, we used Kaplan-Meier curve statistics and compared differences in survival between tumour subtypes with the log rank test. P-values $\leq 0.05$ were considered statistically significant.

Multivariable analysis with Cox regression for OS, RFS and BCSS included age, tumour size and mode of detection. We used SPSS statistics v.26 and STATA IC $\vee 15$ for the statistical analyses.

\section{Results}

\section{Clinical characteristics of the study cohort and surrogate molecular subtypes}

A total of 937 women diagnosed with BC were identified through a search of the regional breast cancer quality of care registry together with the hospital records during the study period. Out of these, 620 women had an invasive tumour $\leq 15 \mathrm{~mm}$ without lymph node metastases on final histology, and 445 of these tumours had sufficient material in the TMA for subtyping (Fig. 1).

The follow-up time ranged from 0.2-29.6 years, with a median of 13.3 years. Median follow-up for women alive was 19.8 years. A high proportion of the tumours were Luminal A-like (47\%) or Luminal Blike $(40 \%)$. Most patients were diagnosed within the screening programme $(71 \%)$, but women with Luminal B-like, Her2-positive or TNBC more often had clinically detected tumours, compared to those with Luminal A-like tumours (34\%, $42 \%$ and $37 \%$ vs $22 \%$ respectively). Women with Luminal B-like, Her $2+$, or TNBC tumours were younger than women with Luminal A-like tumours (mean age 60 years, 57 years, and 57 years vs 62 years, respectively). Locoregional treatment did not differ between the groups. Most of the women $(79 \%)$ received breast conserving surgery (BCS) in combination with radiotherapy (RT). A substantial minority (13\%) were treated with BCS without RT, while the remainder received mastectomy with or without subsequent RT. Administration of systemic adjuvant therapy differed between groups, with endocrine therapy more often given to women with Luminal B-like BC, when compared to patients with Luminal A-like BC ( $29 \%$ vs $20 \%)$. Very few patients $(n=9)$ received chemotherapy, most of those had Her2-positive BC $(n=3)$ or TNBC $(n=4)($ Table 1$)$. 
Table 1

Cohort characteristics

\begin{tabular}{|c|c|c|c|c|c|c|}
\hline & $\begin{array}{l}\text { Whole } \\
\text { cohort } \\
\mathrm{n}=445\end{array}$ & $\begin{array}{l}\text { Luminal A- } \\
\text { like } \\
n=209 \\
(47 \%)\end{array}$ & $\begin{array}{l}\text { Luminal B- } \\
\text { like } \\
n=180 \\
(40 \%)\end{array}$ & $\begin{array}{l}\text { Her2- } \\
\text { positive } \\
n=26 \\
(6 \%)\end{array}$ & $\begin{array}{l}\text { Triple } \\
\text { negative } \\
n=30(7 \%)\end{array}$ & $\begin{array}{l}p \text { - } \\
\text { value }\end{array}$ \\
\hline Age yrs, mean (IQR) & $\begin{array}{l}61(52- \\
68)\end{array}$ & $\begin{array}{l}62(55- \\
69)\end{array}$ & $60(51-68)$ & $\begin{array}{l}57(46- \\
67)\end{array}$ & $57(48-67)$ & 0.03 \\
\hline $\begin{array}{l}\text { Size, mm, mean, } \\
\text { (IQR) }\end{array}$ & $10(8-13)$ & $10(8-12)$ & $11(8-14)$ & $10(7-11)$ & $12(10-15)$ & 0.003 \\
\hline $\begin{array}{l}\text { Mode of detection } \\
\text { - Screening } \\
\text { - Clinical }\end{array}$ & $\begin{array}{l}316(71 \%) \\
129(29 \%)\end{array}$ & $\begin{array}{l}164 \\
(78.5 \%) \\
45(21.5 \%)\end{array}$ & $\begin{array}{l}118 \\
(65.6 \%) \\
62(34.4 \%)\end{array}$ & $\begin{array}{l}15 \\
(57.7 \%) \\
11 \\
(42.3 \%)\end{array}$ & $\begin{array}{l}19(63.3 \%) \\
11(36.7 \%)\end{array}$ & 0.01 \\
\hline $\begin{array}{l}\text { Oestrogen receptors } \\
\text { (ER) } \\
\text { - ER+ } \\
\text { - ER- } \\
\text { - Missing }\end{array}$ & $\begin{array}{l}406 \\
(91.2 \%) \\
38(8.5 \%) \\
1(0.2 \%)\end{array}$ & All & All & $\begin{array}{l}17 \\
(65.4 \%) \\
8(30.8 \%) \\
1(3.8 \%)\end{array}$ & None & - \\
\hline $\begin{array}{l}\text { Locoregional } \\
\text { treatment } \\
\text { - BCS and RT } \\
\text { - Mastectomy and } \\
\text { RT } \\
\text { - Mastectomy w/o } \\
\text { RT } \\
\text { - BCS w/o RT }\end{array}$ & $\begin{array}{l}352 \\
(79.1 \%) \\
7(1.6 \%) \\
30(6.7 \%) \\
56 \\
(12.6 \%)\end{array}$ & $\begin{array}{l}161(77 \%) \\
4(1.9 \%) \\
12(5.7 \%)\end{array}$ & $\begin{array}{l}145 \\
(80.6 \%) \\
3(1.7 \%) \\
12(6.7 \%) \\
20(11.1 \%)\end{array}$ & $\begin{array}{l}21 \\
(80.8 \%) \\
0 \\
3(11.5 \%) \\
2(7.7 \%)\end{array}$ & $\begin{array}{l}25(83.3 \%) \\
0 \\
3(10 \%) \\
2(6.7 \%)\end{array}$ & 0.76 \\
\hline $\begin{array}{l}\text { Endocrine therapy } \\
\text { - Yes } \\
\text { - No }\end{array}$ & $\begin{array}{l}100 \\
(22.5 \%) \\
345 \\
(77.5 \%)\end{array}$ & $\begin{array}{l}167 \\
(79.9 \%)\end{array}$ & $\begin{array}{l}128 \\
(71.1 \%)\end{array}$ & $\begin{array}{l}21 \\
(80.8 \%)\end{array}$ & $\begin{array}{l}1(3.3 \%) \\
29(96.7 \%)\end{array}$ & 0.01 \\
\hline
\end{tabular}

P-values indicate level of significance for overall difference between subtype groups, using chi square test for categorical variables and one way ANOVA for continuous variables.

Abbreviations BC - breast cancer, IQR - interquartile range, BCS - breast conserving surgery,

$R T$ - radiotherapy 


\begin{tabular}{|c|c|c|c|c|c|c|}
\hline & $\begin{array}{l}\text { Whole } \\
\text { cohort } \\
n=445\end{array}$ & $\begin{array}{l}\text { Luminal A- } \\
\text { like } \\
n=209 \\
(47 \%)\end{array}$ & $\begin{array}{l}\text { Luminal B- } \\
\text { like } \\
n=180 \\
(40 \%)\end{array}$ & $\begin{array}{l}\text { Her2- } \\
\text { positive } \\
n=26 \\
(6 \%)\end{array}$ & $\begin{array}{l}\begin{array}{l}\text { Triple } \\
\text { negative }\end{array} \\
n=30(7 \%)\end{array}$ & $\begin{array}{l}p- \\
\text { value }\end{array}$ \\
\hline Chemotherapy & $9(2 \%)$ & 0 & $2(1.1 \%)$ & $3(11.5 \%)$ & $4(13.3 \%)$ & 0.000 \\
\hline $\begin{array}{l}\text { - Yes } \\
\text { - No }\end{array}$ & $436(98 \%)$ & $\begin{array}{l}209 \\
(100 \%)\end{array}$ & $\begin{array}{l}178 \\
(98.9 \%)\end{array}$ & $\begin{array}{l}23 \\
(88.5 \%)\end{array}$ & $26(86.7 \%)$ & \\
\hline \multicolumn{7}{|c|}{$\begin{array}{l}\text { P-values indicate level of significance for overall difference between subtype groups, using chi square } \\
\text { test for categorical variables and one way ANOVA for continuous variables. }\end{array}$} \\
\hline \multicolumn{7}{|c|}{ Abbreviations $B C$ - breast cancer, IQR - interquartile range, BCS - breast conserving surgery, } \\
\hline$R T$ - radiotherapy & & & & & & \\
\hline
\end{tabular}

\section{Overall survival}

A total of 168 women died, whereof 33 from breast cancer. The univariate analysis showed no statistically significant differences in OS between patients based on surrogate tumour subtypes (Fig. 2a). Multivariable analysis showed numerically increased hazard ratios (HR) for the non-Luminal A-like subtypes: 1.07 (Luminal B-like; 95\% confidence interval (Cl) 0.77-1.50), 1.42 (TNBC; 95\% Cl 0.78-2.57), and $1.02(\mathrm{Her} 2+; 95 \% \mathrm{Cl} 0.51-2.04)$ but the differences were not statistically significant. Clinical detection (HR 1.58; $\mathrm{Cl} 1.11-2.23)$ ) and high age (HR 1.10; $\mathrm{Cl} 1.08-1.12)$ increased the risk of dying. Table 2 summarizes the results of the multivariable analysis. 
Table 2

Multivariable analysis of risk factors for overall survival

\begin{tabular}{|c|c|c|c|}
\hline \multicolumn{4}{|c|}{ Multivariable analysis of overall survival } \\
\hline & $\mathrm{n}$ & $\mathrm{HR}(95 \% \mathrm{Cl})$ & p-value \\
\hline \multicolumn{4}{|l|}{ Tumour subtype } \\
\hline Luminal A-like & 209 & Ref. & \\
\hline Luminal B-like & 180 & $1.07(0.77-1.50)$ & 0.69 \\
\hline Triple negative & 30 & $1.42(0.78-2.57)$ & 0.25 \\
\hline Her2-positive & 26 & $1.02(0.51-2.04)$ & 0.96 \\
\hline Clinical detection $^{a}$ & 129 & $1.58(1.11-2.23)$ & 0.01 \\
\hline Tumour size (mm) & & $1.01(0.96-1.07)$ & 0.70 \\
\hline Age (years) & & $1.10(1.08-1.12)$ & $<0.001$ \\
\hline \multicolumn{4}{|c|}{$n$ - number of patients with risk factor, HR - hazard ratio, Ref - reference } \\
\hline \multicolumn{4}{|c|}{$R T$ - radiotherapy, $\mathrm{Cl}$ - confidence interval, a compared to detection by screening } \\
\hline
\end{tabular}

Univariate analysis showed no statistically significant difference in BCSS between subtypes. (Fig. 2b). The 5-, 10-, and 20-year BCSS for the whole cohort were $98 \%, 96 \%$, and $89 \%$, respectively. Table 3 shows the survival rates for the respective subtypes. Of the 33 women who died from breast cancer, 11 had Luminal A-like tumours, 16 had Luminal B-like tumours, four had TNBC and two had Her2-positive tumours. In multivariable analysis the non-Luminal A-like subtypes all had higher HRs than the Luminal A-like (Luminal B-like $1.76(95 \% \mathrm{Cl} 0.80-3.89)$, TNBC $2.18(95 \% \mathrm{Cl} 0.67-7.14)$ and Her2 $+1.40(95 \% \mathrm{Cl}$ $0.31-6.34)$ ) but the differences did not reach statistical significance (Table 4). 
Table 3

Survival rates depending on molecular subtype

\section{Cumulative survival rates depending on molecular subtype}

\begin{tabular}{|c|c|c|c|c|c|c|c|}
\hline & \multicolumn{3}{|c|}{5 years } & \multicolumn{2}{|c|}{10 years } & \multicolumn{2}{|c|}{20 years } \\
\hline & $\mathrm{n}$ & os & BCSS & os & BCSS & os & BCSS \\
\hline All & 445 & $94 \%$ & $98 \%$ & $84 \%$ & $96 \%$ & $60 \%$ & $89 \%$ \\
\hline LumA & 209 & $95 \%$ & $99 \%$ & $86 \%$ & $97 \%$ & $68 \%$ & $93 \%$ \\
\hline LumB & 180 & $94 \%$ & $98 \%$ & $82 \%$ & $96 \%$ & $57 \%$ & $83 \%$ \\
\hline TNBC & 30 & $87 \%$ & $89 \%$ & $70 \%$ & $85 \%$ & $53 \%$ & $85 \%$ \\
\hline Her2+ & 26 & $96 \%$ & $100 \%$ & $88 \%$ & $91 \%$ & $68 \%$ & $91 \%$ \\
\hline
\end{tabular}

Table 4

Multivariable analysis of breast cancer specific survival

\begin{tabular}{|c|c|c|c|}
\hline \multicolumn{4}{|c|}{ Multivariable analysis of breast cancer specific survival } \\
\hline & $\mathrm{n}$ & $\mathrm{HR}(95 \% \mathrm{Cl})$ & p-value \\
\hline \multicolumn{4}{|l|}{ Tumour subtype } \\
\hline Luminal A-like & 209 & Ref. & \\
\hline Luminal B-like & 180 & $1.76(0.80-3.89)$ & 0.16 \\
\hline Triple negative & 30 & $2.18(0.67-7.14)$ & 0.20 \\
\hline Her2-positive & 26 & $1.40(0.31-6.34)$ & 0.67 \\
\hline Clinical detection ${ }^{\mathrm{a}}$ & 129 & $1.39(0.66-2.93)$ & 0.38 \\
\hline Tumour size (mm) & & $1.07(0.96-1.21)$ & 0.24 \\
\hline Age (years) & & $0.99(0.96-1.02)$ & 0.48 \\
\hline \multicolumn{4}{|c|}{$n$ - number of patients with risk factor, $H R$ - hazard ratio, Ref - referenc } \\
\hline
\end{tabular}

\section{Recurrence-free survival}

We found no statistically significant difference in RFS between subgroups in the present cohort either in univariate (Fig. 2c) or multivariable analysis (Table 5). The non-Luminal A-like subtypes, however all had 
higher estimated HRs compared to the Luminal A-like subtype (Luminal B-like $1.40(95 \% \mathrm{Cl} 0.86-2.29)$, TNBC $1.73(95 \% \mathrm{Cl} 0.78-3.85)$ and Her2 + $1.54(95 \% \mathrm{Cl} 0.64-3.69))$

Table 5

Multivariable analysis of recurrence-free survival

\begin{tabular}{|c|c|c|c|}
\hline \multicolumn{4}{|c|}{ Multivariable analysis of recurrence free survival } \\
\hline & $\mathrm{n}$ & $\mathrm{HR}(95 \% \mathrm{Cl})$ & p-value \\
\hline \multicolumn{4}{|l|}{ Tumour subtype } \\
\hline Luminal A-like & 209 & Ref. & \\
\hline Luminal B-like & 180 & $1.40(0.86-2.29)$ & 0.18 \\
\hline Triple negative & 30 & $1.73(0.78-3.85)$ & 0.18 \\
\hline Her2-positive & 26 & $1.54(0.64-3.69)$ & 0.33 \\
\hline Clinical detection ${ }^{\mathrm{a}}$ & 129 & $1.46(0.90-2.36)$ & 0.12 \\
\hline Tumour size (mm) & & $1.01(0.94-1.09)$ & 0.80 \\
\hline Age (years) & & $0.99(0.97-1.01)$ & 0.38 \\
\hline \multicolumn{4}{|c|}{$n$ - number of patients with risk factor, $H R$ - hazard ratio, Ref - reference } \\
\hline \multicolumn{4}{|c|}{$\mathrm{Cl}$ - confidence interval, ${ }^{\text {a }}$ compared to detection by screening } \\
\hline
\end{tabular}

\section{Locoregional and distant recurrence}

In total 60 women $(13 \%)$ had locoregional recurrence and 34 women $(8 \%)$ had distant metastasis. We found no statistically significant difference in locoregional recurrence across subtypes (Fig. 3a). By contrast, there was a difference in the incidence of distant metastasis where the TNBC (HR $3.44 ; 95 \% \mathrm{Cl}$ 1.20-9.91) and Luminal B-like (HR 2.13; $\mathrm{Cl} 1.00-4.56)$ had more distant metastases as compared with the Luminal A-like subtype. Distant recurrence occurred early in TNBC, and later in the Luminal B-like BC, hence the difference between these two groups gradually diminished with longer follow-up (Fig. 3b).

More extensive models for multivariable analysis of OS, BCSS, and RFS including treatment variables (radiotherapy, type of surgery, chemotherapy and endocrine therapy) did not substantially change the estimated hazard ratios for the different subtypes (data not shown).

\section{Discussion}

No certain association of surrogate molecular subtypes with overall survival was found in this population-based cohort of women with small node negative breast cancers $(\mathrm{BC})$ and a very long follow up time. Women with small TNBC or Luminal B-like tumours were however three times (TNBC) or twice (Luminal B-like) as likely to have had a distant recurrence compared to woman with a Luminal A-like 
tumour after 20 years. These women also had worse BCSS compared to women with Luminal A-like tumours, although the difference was not statistically significant. Women with Her2 + tumours had neither worse BCSS, nor higher incidence of distant recurrence than the women with Luminal A-like tumours, despite not receiving any targeted anti-Her2 therapy.

\section{TNBCs are more aggressive and may merit systemic therapy even when they are small}

Women with TNBC fared worse than women with Luminal A-like tumours in terms of OS, BCSS and RFS although differences were statistically significant only for distant recurrences. Our findings are supported by a SEER database study showing that women with pT1abNO ER-tumours more often died from BC and those with ER + more often of other causes, [15] as well as other studies showing that TNBC is associated with worse RFS and distant RFS in pT1abN0[16] or pT1bN0 tumours.[9] Thus, it would seem prudent to consider chemotherapy even for small node negative TNBC. Indeed, results from older prospective trials show a benefit of chemotherapy for ER-pT1abN0 tumours [17] Several newer retrospective studies, however, failed to show any association between chemotherapy and outcome in pT1abNO TNBC tumours, $[16,18,19]$ emphasizing the need for prospective trials on this group of patients, receiving modern locoregional therapy and using relevant definitions of hormone receptor status and Her2-status.

\section{Small Her2-positive tumours have a favourable prognosis even in the absence of Her2-targeted therapy}

The most surprising finding in our study was that Her2-positive tumours did not have a significantly worse long-term outcome compared to Luminal A-like tumours, even though no patient received targeted Her2 therapy. The numbers are small and warrant a cautious interpretation but are nonetheless interesting. Her2-positivity had no association with OS, possibly because women with Her2 + tumours were younger on average, a finding consistent with other studies. $[10,20]$ The BCSS was worse compared to Luminal A-like tumours after 10 years ( $91 \%$ vs $97 \%$ ) but after this the difference evened out. The only analysis where the Her2 + tumours stood out was in the locoregional recurrences where the cumulative incidence was fourfold higher after five years and still almost twice as high compared to Luminal A-like tumours after 20 years. Other retrospective studies have also failed to show Her2-positivity in pT1abN0 BC being an independent factor for worse DFS [20] or distant RFS.[8]

In contrast, two retrospective studies have shown worse RFS and distant RFS for Her2 + pT1abN0 tumours[7] or pT1bN0 tumours[9], respectively. The second study did not, however, find any worse outcome for Her2 + pT1aN0 tumours. Another retrospective study described worse RFS and BCSS for Her2 + pT1mic/ab N0 tumours.[6]

One of the reasons for the conflicting results in the literature may be how the molecular surrogate Her2positive group is defined. By the original definition, "Her2-enriched" is ER-negative [2] but many authors define it as Her 2 + regardless of hormone receptor status, as was also the case for the present cohort. The 
rationale behind this is that treatment recommendations generally do not consider ER-status in Her2 + BC. $[21,22]$ In our cohort, most $(17 / 26)$ Her2 + tumours were ER+, but the BC deaths and the distant recurrences all occurred in the Her2+/ER- subgroup, while locoregional recurrences occurred equally in the Her2+/ER- and Her2+/ER + groups. Furthermore, there are retrospective studies showing a benefit only of endocrine therapy alone (for Her2+/ER + tumours) but not chemotherapy with/without trastuzumab, for women with Her2-positive pT1abNO tumours. $[19,20]$ A retrospective study describing a better OS for patients with Her2-positive pT1abN0 tumours receiving trastuzumab and chemotherapy [23] included women who received only chemotherapy, only endocrine therapy or no adjuvant treatment at all in the same comparison group making the results somewhat hard to disentangle. Together with our findings, this suggests that small node negative Her2 + tumours have a good prognosis if they are ER+, and hence that the benefits of adding chemotherapy and Her2-targeted therapy on top of endocrine therapy may not be substantial.

\section{Outcome of Luminal B-like tumours depends strongly on the length of follow-up}

The natural course of $\mathrm{BC}$ varies depending on subtype, where the Luminal-like tumours have a slow but steady rate of recurrence and death over the years, while the Her2 + and TNBC have a higher mortality rate initially, which declines after the first five years $[24,25]$ The rate of recurrence and death for Luminal B-like tumours is only slightly higher than for the Luminal A-like, with almost no difference at five years of follow up, but after 20 years actually being on the same level as TNBC. In our cohort the 5-year BCSS were similar 99\% (Luminal A-like) and 98\% (Luminal B-like), but after 20 years had diverged to 93\% (Luminal A-like) and 83\% (Luminal B-like). The same held true for both locoregional and distant recurrences. Our findings are consistent with a recent registry-based study with long term follow up in which Luminal B-like and TNBC eventually had the same risk of BC events. [26] Only a third of the women with Luminal B-like tumours in the present cohort received endocrine therapy and a tenth received lumpectomy without subsequent RT, which certainly influenced the long-term outcome.[27] Today, endocrine therapy would have been recommended for all of them, and likely none would have had BCS without RT. These results suggest that the possible benefit from addition of chemotherapy is highly dependent on the expected life span of the woman.

\section{Strenghts And Limitations}

A limitation of this study is that the number of patients with Her2-positive and TNBC is relatively low, consistent with other reports on small breast carcinomas $[6,20]$ The relatively small number of Her2positive tumours also prohibited further subdivision of these patients into ER + and ER- groups. Using surrogate molecular subtypes, rather than the actual molecular subtypes based on gene expression analysis may also be considered a weakness, since these do not correlate perfectly [28]. On the other hand, surrogate molecular subtypes are currently used in clinical practice in many settings and the molecular subtypes can also vary depending on signature and gene expression test used [29]. The use of TMAs rather than whole tissue slides means a risk of not evaluating a representative section of the 
tumour. Since the tumours included in this study are small, this risk is low and may primarily be a problem in the Ki67 evaluation and hence in the distinction between a subset of the Luminal A-like and Blike tumours. Likewise, the need to use nuclear rather than histological grade should also only affect the ability to distinguish between Luminal A-like and Luminal B-like tumours. However, the resulting groups had measurably different outcomes, which indicates that both Ki67 evaluation in TMA and use of nuclear grade resulted in an acceptable method of distinction between these Luminal groups. The clinicopathological factors used to guide treatment during the recruitment period of the cohort correlates with breast cancer subtypes and may have influenced analysis of the association between prognosis and subtype. At the time of treatment, modern protocols were however not in practice and few women were given adjuvant systemic treatment.

The strengths of this study include a very long follow-up with no patients lost to follow up. This is in contrast with most of the currently available studies for this patient group, and essential for analysing the outcome of the Luminal B-tumours. This means that the accuracy of the findings is high, compared to the data that may be extracted from a registry. The cohort is population based, including $>90 \%$ of women operated for $\mathrm{BC}$ in one health care region during the time period of inclusion, making it representative for women with small lymph node negative $\mathrm{BC}$ at that time. There was no difference in primary surgery or RT between the groups, indicating that they were probably comparable with respect to co-morbidity. None of the women with Her2-positive tumours were treated with targeted therapy, making it possible to observe the natural course of these tumours. Finally, the histological evaluation was done by the same two subspecialised breast pathologists, reducing interobserver variation.

\section{Conclusion}

Small TNBC and Luminal B-like tumours behave more aggressively than Luminal A-like tumours. These subtypes follow different courses, where the TNBC recur mostly early on or not at all, while the Luminal Blike tumours recur at a slow but consistent rate over the years. This means that a young and otherwise healthy woman with a stage 1 Luminal B tumour might benefit substantially from systemic adjuvant therapy, while for an older woman the risks may outweigh the benefits. For early stage TNBC, our study confirms a high 10-year risk of recurrence and death, and thus patients should stand to gain from systemic adjuvant therapy. For the women with Her2 + tumours however, neither our findings, nor the available literature unequivocally support an increased risk of distant metastasis or death for pT1abN0tumours in absence of Her2-targeted treatment. It is possible that treatment recommendations for Her2 + tumours need to take ER-status into account, and that women with ER+/Her2 + tumours have no need for adjuvant therapy in addition to locoregional radiotherapy and endocrine treatment. Despite the different risks associated with the subtypes described above, no association of tumour subtype with OS was observed. Prospective trials using modern locoregional therapy and endocrine therapy are thus needed to evaluate whether the more aggressive behaviour non-Luminal A-like subtypes translate into a benefit of systemic adjuvant chemotherapy and Her2-targeted therapy for women with small lymph node negative $\mathrm{BC}$. 


\section{Declarations}

\section{Funding}

This study was supported by grants from the Lions Cancer Research Foundation in Uppsala, Swedish Breast Cancer Association, the Percy Falk Foundation, VISARE NORR funding of the Northern County Councils Regional Federation (grant no: VISARENORR750491 and VISARENORR931408) and ALF funding from Region Västerbotten.

\section{Conflicts of interests}

None.

\section{Availability of data and material}

Data is not uploaded to a publicly available platform. Researchers have access to data through application to the study PI (malin.sund@umu.se) or the corresponding author under standard rules of protecting data integrity and existing ethics permissions.

\section{Code availability}

Not applicable.

\section{Authors contributions}

Gunilla Rask - histologic examination of the material, data analysis and interpretation, draft writing. Anoosheh Nazemroaya - histologic examination of the material, critical review of the final draft.

Malin Jansson - data analysis, critical review of the final draft.

Charlotta Wadsten - data interpretation, critical review of the final draft.

Fredrik Wärnberg - acquisition of surgical specimens, construction of TMA and acquisition of patient data. Critical review of the final draft.

Lars Holmberg - conception of study and critical review of the final draft.

Greger Nilsson - conception of study and critical review of the final draft.

Carl Blomqvist - conception of study and critical review of the final draft.

Malin Sund - conception and design of study, data interpretation and manuscript drafting.

\section{Ethics approval}

Record number 99 422, 2005:118, and 2005:118/2; The Regional Ethics Committee of Uppsala 
Consent to participate

After approval of the regional Ethics Committee, no patients were informed of the study, since the material and information was gathered after such time that any result of the study could not affect treatment decision for the women studied.

Consent for publication

Not applicable.

\section{Acknowledgements}

Johan Svensson at Umeå school of Business, Economics and Statistics for kind and patient help with statistical analyses.

\section{References}

1. NKBC [https://statistik.incanet.se/brostcancer/]

2. Sorlie T, Perou CM, Tibshirani R, Aas T, Geisler S, Johnsen H, Hastie T, Eisen MB, van de Rijn M, Jeffrey SS et al: Gene expression patterns of breast carcinomas distinguish tumor subclasses with clinical implications. Proc Natl Acad Sci U S A 2001, 98(19):10869-10874. doi:10.1073/pnas.191367098

3. Piccart-Gebhart MJ, Procter M, Leyland-Jones B, Goldhirsch A, Untch M, Smith I, Gianni L, Baselga J, Bell R, Jackisch $\mathrm{C}$ et al: Trastuzumab after Adjuvant Chemotherapy in HER2-Positive Breast Cancer. New England Journal of Medicine 2005, 353(16):1659-1672. doi:10.1056/NEJMoa052306

4. Gianni L, Pienkowski T, Im Y-H, Roman L, Tseng L-M, Liu M-C, Lluch A, Staroslawska E, de la HabaRodriguez J, Im S-A et al: Efficacy and safety of neoadjuvant pertuzumab and trastuzumab in women with locally advanced, inflammatory, or early HER2-positive breast cancer (NeoSphere): a randomised multicentre, open-label, phase 2 trial. The Lancet Oncology 2012, 13(1):25-32. doi:10.1016/S1470-2045(11)70336-9

5. Hugh J, Hanson J, Cheang MCU, Nielsen TO, Perou CM, Dumontet C, Reed J, Krajewska M, Treilleux I, Rupin $\mathrm{M}$ et al: Breast Cancer Subtypes and Response to Docetaxel in Node-Positive Breast Cancer: Use of an Immunohistochemical Definition in the BCIRG 001 Trial. Journal of Clinical Oncology 2009, 27(8):1168-1176. doi:10.1200/jco.2008.18.1024

6. Cancello G, Maisonneuve P, Rotmensz N, Viale G, Mastropasqua MG, Pruneri G, Montagna E, Dellapasqua $S$, lorfida M, Cardillo A et al: Prognosis in women with small (T1mic,T1a,T1b) nodenegative operable breast cancer by immunohistochemically selected subtypes. Breast Cancer Res Treat 2011, 127(3):713-720. doi:10.1007/s10549-011-1465-7

7. Gonzalez-Angulo AM, Litton JK, Broglio KR, Meric-Bernstam F, Rakkhit R, Cardoso F, Peintinger F, Hanrahan EO, Sahin A, Guray M et al: High risk of recurrence for patients with breast cancer who have human epidermal growth factor receptor 2-positive, node-negative tumors $1 \mathrm{~cm}$ or smaller. $J$ Clin Oncol 2009, 27(34):5700-5706. doi:10.1200/JC0.2009.23.2025 
8. Livi L, Meattini I, Saieva C, Franzese C, Di Cataldo V, Greto D, Franceschini D, Scotti V, Bonomo P, Nori $\mathrm{J}$ et al: Prognostic value of positive human epidermal growth factor receptor 2 status and negative hormone status in patients with T1a/T1b, lymph node-negative breast cancer. Cancer 2012, 118(13):3236-3243. doi:10.1002/cncr.26647

9. Park YH, Kim ST, Cho EY, Choi YL, Ok ON, Baek HJ, Lee JE, Nam SJ, Yang JH, Park W et al: A risk stratification by hormonal receptors (ER, PgR) and HER-2 status in small $(<$ or $=1 \mathrm{~cm}$ ) invasive breast cancer: who might be possible candidates for adjuvant treatment?Breast Cancer Res Treat 2010, 119(3):653-661. doi:10.1007/s10549-009-0665-x

10. Kolben T, Harbeck N, Wuerstlein R, Schubert-Fritschle G, Bauerfeind I, Schrodi S, Engel J: Endocrine sensitivity is decisive for patient outcome in small node-negative breast cancers (BC) (pT1a,b) results from the Munich Cancer Registry. Breast 2015, 24(1):24-31. doi:10.1016/j.breast.2014.10.007

11. Wolff AC, Hammond MEH, Allison KH, Harvey BE, Mangu PB, Bartlett JMS, Bilous M, Ellis IO, Fitzgibbons P, Hanna W et al: Human Epidermal Growth Factor Receptor 2 Testing in Breast Cancer: American Society of Clinical Oncology/College of American Pathologists Clinical Practice Guideline Focused Update. J Clin Oncol 2018, 36(20):2105-2122. doi:10.1200/jco.2018.77.8738

12. Elston CW, Ellis IO: Pathological prognostic factors in breast cancer. I. The value of histological grade in breast cancer: experience from a large study with long-term follow-up. C. W. Elston \& I. O. Ellis. Histopathology 1991; 19; 403-410. Histopathology 2002, 41(3a):151-152, discussion 152-153.

13. Ehinger A, Malmström P, Bendahl PO, Elston CW, Falck AK, Forsare C, Grabau D, Rydén L, Stål O, Fernö $\mathrm{M}$ : Histological grade provides significant prognostic information in addition to breast cancer subtypes defined according to St Gallen 2013. Acta Oncol 2017, 56(1):68-74.

doi:10.1080/0284186x.2016.1237778

14. Maisonneuve P, Disalvatore D, Rotmensz N, Curigliano G, Colleoni M, Dellapasqua S, Pruneri G, Mastropasqua MG, Luini A, Bassi F et al: Proposed new clinicopathological surrogate definitions of luminal A and luminal B (HER2-negative) intrinsic breast cancer subtypes. Breast Cancer Res 2014, 16(3):R65-R65. doi:10.1186/bcr3679

15. Hanrahan EO, Gonzalez-Angulo AM, Giordano SH, Rouzier R, Broglio KR, Hortobagyi GN, Valero V: Overall survival and cause-specific mortality of patients with stage T1a,bNOMO breast carcinoma. J Clin Oncol 2007, 25(31):4952-4960. doi:10.1200/jco.2006.08.0499

16. Kwon JH, Kim YJ, Lee KW, Oh DY, Park SY, Kim JH, Chie EK, Kim SW, Im SA, Kim IA et al: Triple negativity and young age as prognostic factors in lymph node-negative invasive ductal carcinoma of $1 \mathrm{~cm}$ or less. BMC Cancer 2010, 10:557. doi:10.1186/1471-2407-10-557

17. Fisher B, Redmond C, Dimitrov NV, Bowman D, Legault-Poisson S, Wickerham DL, Wolmark N, Fisher ER, Margolese R, Sutherland C et al: A randomized clinical trial evaluating sequential methotrexate and fluorouracil in the treatment of patients with node-negative breast cancer who have estrogenreceptor-negative tumors. N Engl J Med 1989, 320(8):473-478. doi:10.1056/nejm198902233200801

18. Ho AY, Gupta G, King TA, Perez CA, Patil SM, Rogers KH, Wen YH, Brogi E, Morrow M, Hudis CA et al: Favorable prognosis in patients with T1a/T1bN0 triple-negative breast cancers treated with 
multimodality therapy. Cancer 2012, 118(20):4944-4952. doi:https://doi.org/10.1002/cncr.27480

19. Olszewski AJ, Migdady Y, Boolbol SK, Klein P, Boachie-Adjei K, Sakr BJ, Sikov W, Shao T: Effects of adjuvant chemotherapy in HER2-positive or triple-negative pT1ab breast cancers: a multi-institutional retrospective study. Breast Cancer Research and Treatment 2013, 138(1):215-223. doi:10.1007/s10549-013-2423-3

20. Bao J, Donovan C, Amersi F, Zhang X, Giuliano AE, Chung A: Outcomes in patients with small nodenegative invasive breast cancer. Breast J 2019, 25(4):638-643. doi:10.1111/tbj.13288

21. Nationellt Vårdprogram - Bröstcancer

[https://www.cancercentrum.se/samverkan/cancerdiagnoser/brost/vardprogram/gallandevardprogram]

22. Tryfonidis K, Zardavas D, Cardoso F: Small breast cancers: when and how to treat. Cancer Treat Rev 2014, 40(10):1129-1136. doi:10.1016/j.ctrv.2014.09.004

23. Ignatov $T$, Eggemann $H$, Burger $E$, Costa SD, Ignatov A: Management of small T1a/b breast cancer by tumor subtype. Breast Cancer Res Treat 2017, 163(1):111-118. doi:10.1007/s10549-017-4168-x

24. Chia SK, Speers CH, Bryce CJ, Hayes MM, Olivotto IA: Ten-Year Outcomes in a Population-Based Cohort of Node-Negative, Lymphatic, and Vascular Invasion-Negative Early Breast Cancers Without Adjuvant Systemic Therapies. Journal of Clinical Oncology 2004, 22(9):1630-1637. doi:10.1200/jco.2004.09.070

25. Blows FM, Driver KE, Schmidt MK, Broeks A, van Leeuwen FE, Wesseling J, Cheang MC, Gelmon K, Nielsen TO, Blomqvist $\mathrm{C}$ et al: Subtyping of breast cancer by immunohistochemistry to investigate a relationship between subtype and short and long term survival: a collaborative analysis of data for 10,159 cases from 12 studies. PLoS Med 2010, 7(5):e1000279. doi:10.1371/journal.pmed.1000279

26. Jaraj D, Clinical Epidemiology Division DoMSKISS, Department of Surgery CStGHSS, Höijer J, Unit of Biostatistics IoEMKISS, Widman L, Unit of Biostatistics loEMKISS, Ahlgren J, Department of Oncology FoM, Health ÖUÖS et al: Long-term prognostication for 20,114 women with small and node-negative breast cancer (T1abN0). JNCl Cancer Spectrum 2020. doi:10.1093/jncics/pkaa084

27. Davies C, Godwin J, Gray R, Clarke M, Cutter D, Darby S, McGale P, Pan HC, Taylor C, Wang YC et al: Relevance of breast cancer hormone receptors and other factors to the efficacy of adjuvant tamoxifen: patient-level meta-analysis of randomised trials. Lancet 2011, 378(9793):771-784. doi:10.1016/s0140-6736(11)60993-8

28. Lundgren C, Bendahl PO, Borg Å, Ehinger A, Hegardt C, Larsson C, Loman N, Malmberg M, Olofsson $\mathrm{H}$, Saal LH et al: Agreement between molecular subtyping and surrogate subtype classification: a contemporary population-based study of ER-positive/HER2-negative primary breast cancer. Breast Cancer Res Treat 2019, 178(2):459-467. doi:10.1007/s10549-019-05378-7

29. Bartlett JMS, Bayani J, Marshall A, Dunn JA, Campbell A, Cunningham C, Sobol MS, Hall PS, Poole CJ, Cameron DA et al: Comparing Breast Cancer Multiparameter Tests in the OPTIMA Prelim Trial: No Test Is More Equal Than the Others. Journal of the National Cancer Institute 2016, 108(9):djw050. doi:10.1093/jnci/djw050 


\section{Figures}

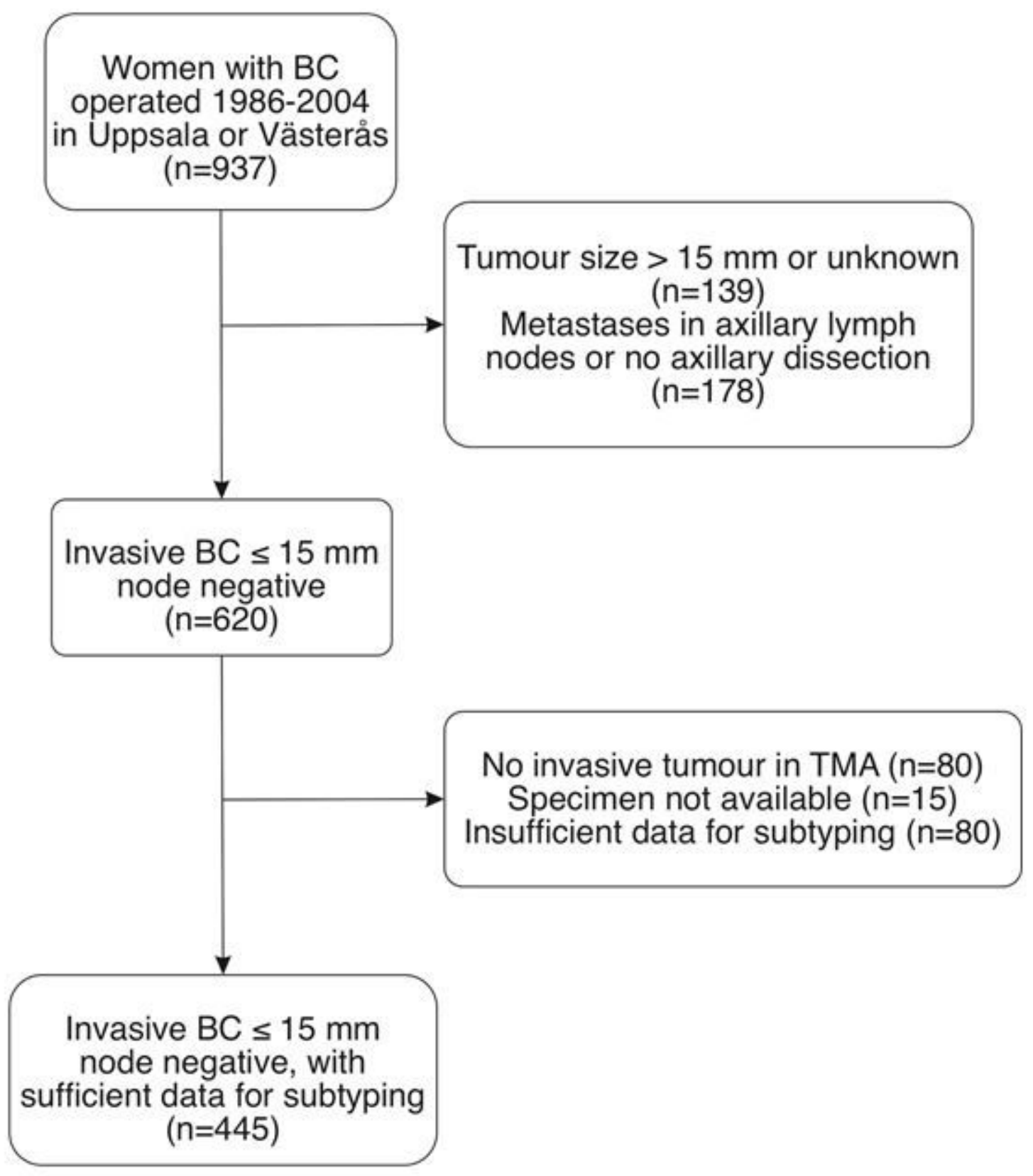

Figure 1

Selection of patients for the study cohort. BC - breast cancer, TMA - tissue microarray. 
a) Overall survival

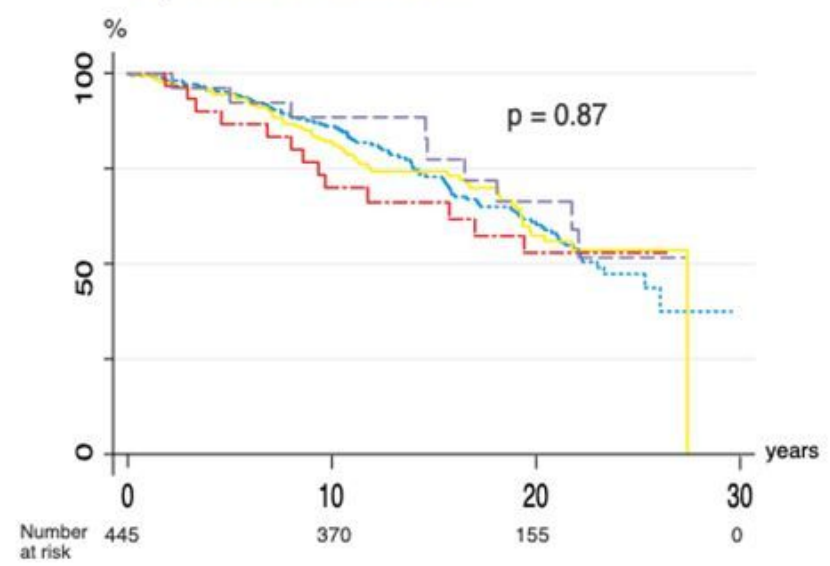

c) Recurrence-free survival

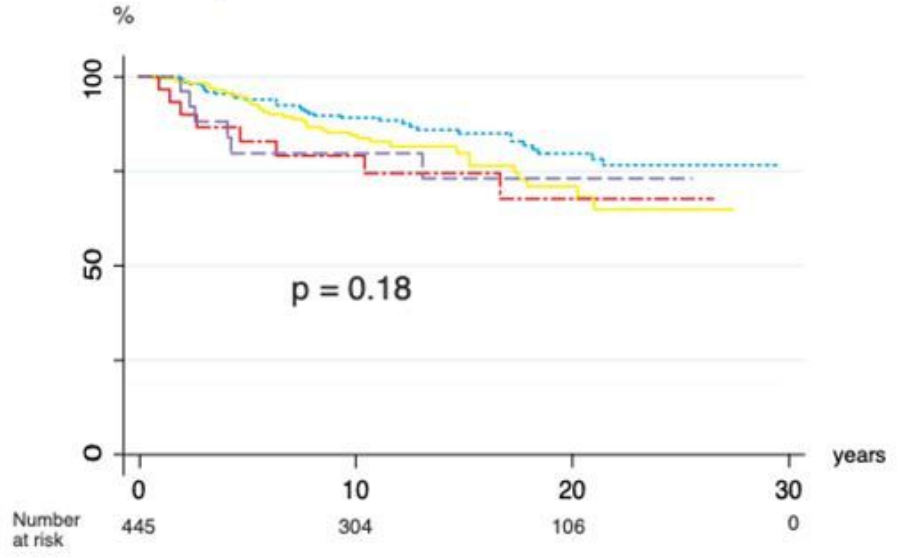

b) Breast cancer-specific survival

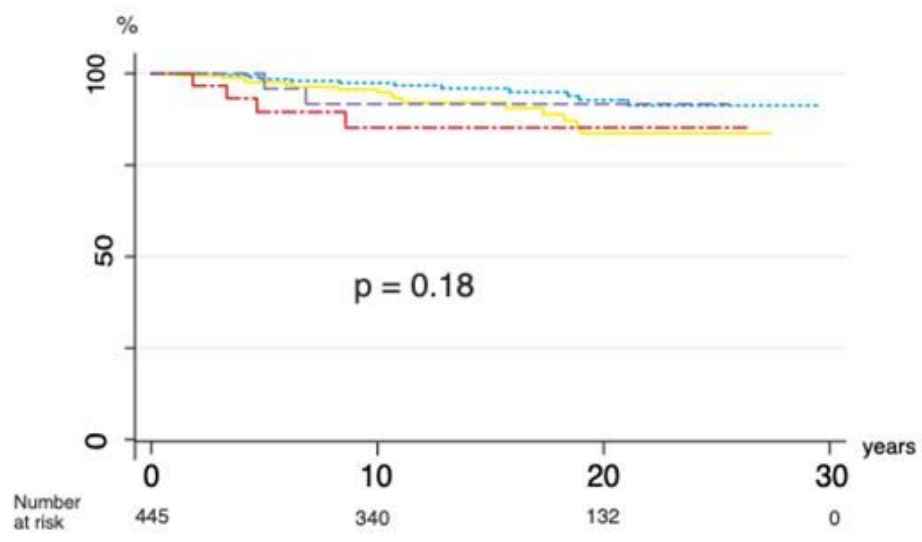

\section{Figure 2}

Survival outcomes (Kaplan Meier) a) Overall survival b) Breast cancer-specific survival c) Recurrence-free survival 

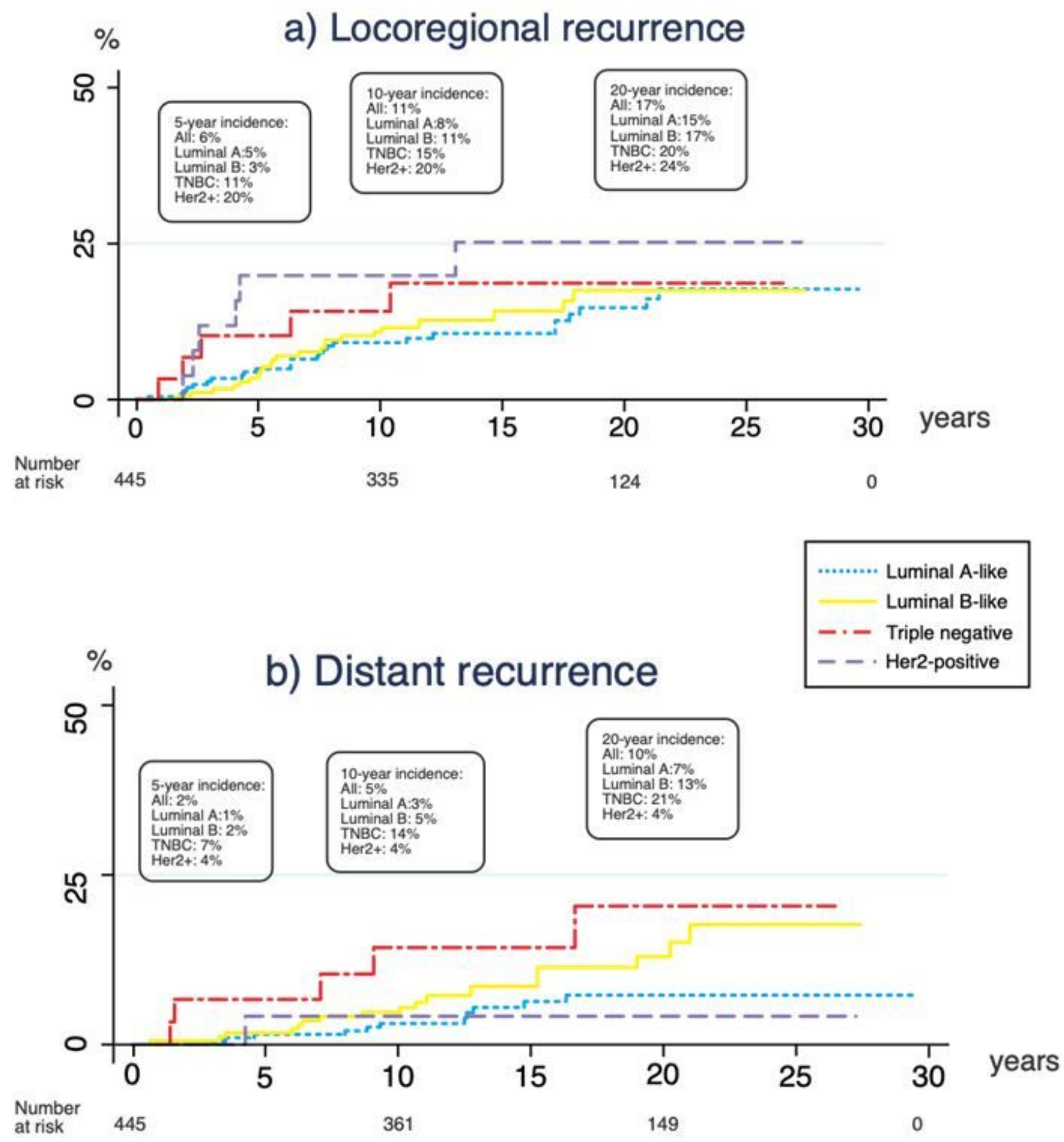

Figure 3

Cumulative incidence of locoregional (a) and distant recurrence (b) 